\title{
Mário de Andrade : un ethnographe des tropiques
}

Résumé: Dans la constitution du concept de modernité au cours des années 1920 au Brésil, Mário de Andrade (1893-1945) soutenait la nécessité d'envisager une rupture avec les modèles européens, en introduisant une autre modalité quant à la perception des manifestations artistiques propres à la culture populaire et à leurs multiples dédoublements. Par deux voyages entrepris dans le Nord et le Nord-Est du Brésil (mai-août 1927 et décembre 1928-février 1929), l'écrivain réalise le déplacement nécessaire pour réfléchir sur sa mission en tant que chercheur et spécialiste de culture populaire.

Mots clés: Mário de Andrade, culture populaire, voyage, ethnographie, modernité.

Dans cette étude, notre perspective d'analyse se concentre sur $O$ turista aprendiz [L’Apprenti touriste], publié après la mort de M. de Andrade en 1976 sous la coordination de Telê Ancona Lopez et dont la réédition, en 2015, a été codirigée par Tatiana Longo Figueiredo, avec la collaboration de Leandro Raniero Fernandes (Andrade 2015b). Dans ses deux voyages entrepris dans le Nord (en Amazonie) et le Nord-Est du Brésil (de mai à août 1927 et de décembre 1928 à février 1929), Mário de Andrade fait le déplacement nécessaire pour réfléchir sur son importante mission en tant qu'écrivain moderniste et chercheur, spécialiste de culture populaire. Dans la façon d'aborder ces voyages, le recoupement se manifeste dans le journal de 1928-1929, quand il part pour le Nord-Est en mission d'étude (Rio Grande do Norte, Pernambouc, Paraíba, en passant par Salvador et Maceió), ayant l'obligation non seulement de réaliser une recherche, mais aussi de la rédiger sous forme de chroniques, en vue de les publier dans la presse. Ce texte est d'autant plus intéressant qu'il exploite certains commentaires relatifs au rôle de l'intellectuel comme participant à la construction de l'image culturelle du pays et ce, au travers d'une sensibilité aigüe aux concepts de populaire, de modernité et de narrativité, perceptibles dans la façon d'interpréter des questions qui motivèrent l'ouverture du modernisme à sa lente et complexe définition. S'y réitère aussi l'expérience nouvelle du voyageur, nourri par des lectures déjà faites dans l'univers de cette culture, mais qui se confronte désormais avec la présence d'une réalité transfigurée, d'images et de sonorités peu familières. L'esprit de collectionneur d'œuvres d'art, d'objets artisanaux, d'art sacré et de documents musicaux 
est attisé par le désir de rendre compte des rituels et des danses populaires du Nord-Est, recueillis in loco et perpétués par l'écriture. Travail et loisir participent ensemble à l'expérience de l'apprenti touriste, de l'ethnographe qui se prépare aux terrains futurs et se comporte selon la tendance de l'époque, durant laquelle intellectuels et artistes se distanciaient de leurs cultures d'origine à la recherche d'une nouvelle vision artistique.

Il n'est pas nouveau d'affirmer qu'il s'agit là de l'entreprise ethnographique de Mário de Andrade dans toute son ampleur, que ce soit en littérature ou dans le domaine de la recherche musicale et folklorique, motivée par la curiosité moderniste face aux thèmes nationaux et à la diversité culturelle comme trait différenciateur. Cependant, la coïncidence avec les pratiques exercées en France dans les années 1920 et décrites, selon James Clifford, comme « ethnographie surréaliste », mérite d’être ici mieux précisée. Artistes et écrivains dissidents du mouvement surréaliste, comme Georges Bataille, Michel Leiris ou Antonin Artaud, entre autres, réunis autour de la revue Documents, tirent profit de la dimension ethnographique de l'art en questionnant un de ses principes d'exclusion, à savoir la séparation entre « haute » et " basse » culture. Les manifestations non occidentales de l'art, la réactivation de savoirs mythiques, archaïques et ritualistes portaient encore la marque de l'héritage surréaliste. L'art « primitif » africain, par le déplacement opéré dans la pensée européenne, fait monter d'un grade les valeurs avant-gardistes, en plus de susciter des transformations quant à l'authenticité et à l'hégémonie des manifestations artistiques. Selon Clifford,

[1]e surréalisme ethnographique, différemment tant du critique d'art classique que de l'anthropologue de l'époque, se régale avec les impuretés culturelles et les syncrétismes perturbateurs. Griaule faisait équivaloir l'appréciation des Européens pour l'art africain au goût africain pour les tissus, les bidons d'essence, l'alcool et les armes à feu. Si les Africains préfèrent ne pas imiter nos produits de haute culture, tant pis [...]. (Clifford 2008, 149 ; les traductions du portugais sont de notre fait)

L'anthropologue relève l'inexistence, à l'époque, de l'institution d'une science sociale définie, qui aurait eu ses méthodes et des textes classiques, qui aurait été un champ fertile pour l'instauration d'une critique culturelle subversive dans laquelle on aurait évoqué l'apparat mythique, insolite et exotique des arts orientaux. Dans le processus déstabilisateur de l'eurocentrisme, le mouvement se distinguait par la rupture de la dimension hiérarchique face aux cultures, soumises à des critères valorisants de même poids. La création en 1929, par Bataille, de la revue Documents qui regroupait écrivains et futurs chercheurs de terrain, serait l'exemple de la collaboration ethnographique surréaliste. La configuration du périodique, par la multiplicité d'intentions et par l'utilisation de processus 
semblables au collage, ébauchait avec ses superpositions d'objets, de textes et d'étiquettes l'image d'un musée ethnographique. La juxtaposition, méthode constructive de l'esthétique surréaliste, et la tendance anthropologique de la revue favorisèrent, toujours selon Clifford, la fondation de futurs musées ethnographiques à Paris, exposant de façon hétéroclite leurs objets. La culture devient un bien que l'on collecte, mais de façon à perturber et brouiller les dispositions traditionnelles des symboles établis :

La méthode basique de la revue est la juxtaposition - le collage fortuit et ironique. La disposition adéquate des symboles et artefacts culturels est constamment remise en question. La « haute » tradition artistique est mélangée aux photos agrandies de façon répulsive d'énormes doigts de pied ; artisanat populaire ; copies de Fantômas (fameuse série fantastico-policière) ; décors hollywoodiens ; masques africains, mélanésiens, précolombiens et aussi masques de carnaval français ; comptes rendus de spectacle de music hall ; descriptions des abattoirs de Paris. (Clifford 2008, 151)

Ce musée imaginaire trouve chez Mário de Andrade une correspondance immédiate, quand il adhère à la pratique du collectionneur d'objets artisanaux, artistiques et ethnographiques, en plus de se libérer de la rigueur de l'enquête. Bien qu'il n'y ait pas de référence directe aux représentants de l'ethnographie surréaliste, la lecture de Lévy-Bruhl, Tylor et Frazer par l'écrivain met en évidence son intérêt pour les thèmes ethnographiques. Dans l'écriture de Macunaíma (trad. fr. : Macounaïma), l'appropriation des textes de Koch Grünberg sur les mythes indigènes est bien connue. La mise en catalogue des différents types de manifestations artistiques brésiliennes correspondait à la vocation du chercheur qui se nourrissait de ses propres archives et de celles d'autrui pour la production d'une œuvre à mi-chemin entre art et document, culture savante et populaire, établissant une distance moindre entre eux. Dans la construction de Macunaíma, le « héros sans caractère ", publié à l'époque de ses voyages dans le Nord et le Nord-Est (1928), se trouve le spectre d'un musée populaire en mouvement, dans lequel se juxtaposent objets, légendes, personnages et les mythes les plus variés.

En 1924, sous la conduite du poète franco-suisse Blaise Cendrars, les modernistes paulistes étaient déjà partis pour les villes historiques du Minas Gerais en un "Voyage de découverte du Brésil », à la recherche de la veine baroque, substitut national de l'art nègre, du primitivisme choisi par les Français pour la redéfinition du moderne. Dans ses chroniques, Mário de Andrade allait faire lui aussi le compte rendu du voyage de 1924, quand la nouvelle forme de découvertes commence à se joindre à la tradition, portée par le respect envers l'archaïque et les coutumes provinciales faisant pendant aux coutumes des métropoles. L'aventure dans le Nord et le Nord-Est du pays, peu de temps après ce précédent voyage, révèlera un autre champ d'intérêt, cette fois-ci la culture populaire et la notation de 
musiques, danses et rites, bien que l'objectif soit resté le même : le déplacement culturel comme ouverture aux différentes conceptions esthétiques.

\section{Entre document et fiction}

Eh ! vents, vents de Natal me traversant comme si j'étais un voile. Je suis voile. Je ne couvre pas le paysage, je n'ai pas l'obligation de voir des choses exotiques ... Je suis en train de vivre la vie de mon pays ... (Andrade 2015b, 310)

Telê Ancona Lopez et Tatiana Longo Figueiredo, dans la présentation de la seconde édition commentée de L'Apprenti touriste, relèvent la nature hybride du texte, par son aspect à la fois documentaire et fictionnel, confirmé tant dans le voyage de Mário de Andrade dans le Nord que dans celui du Nord-Est. La recréation de la réalité observée reçoit les nuances du romancier et offre au lecteur une narration qui enrichit la recherche et s'impose comme une interprétation fine des rituels et des sources populaires. Comme poète, il reconnaît dans le matériel collecté des ressources pour les aspects importants de son œuvre moderniste, engagée dans la construction d'identités nationales, imprégnées par de nombreux éléments et acteurs. La recréation fictionnelle des données recueillies, des paysages et des lieux visités, apporte au voyageur la sensation d'y être également intégré, que ce soit par le rapprochement ou par l'éloignement relatifs aux faits :

Ce qui donne indiscutablement une saveur à la lecture des journaux de ses deux voyages est, certainement, l'entrecroisement du récit du voyage réel mis en scène avec le récit issu du voyage imaginaire, accompli par un chroniqueur muni de son expérience de lecture, voyageur qui a pour compagne l'invention. (Figueiredo et Lopez 2015, 37)

L'exploration de nouveaux genres par les Modernistes s'inscrit aussi dans leur indéfinition, par le fait qu'ils aient considéré comme floues les différences qui les singularisaient, optant pour une écriture nomade et indisciplinée. Poésie, fiction, journal, chronique ou roman dialoguaient entre eux, au point de rompre leur propre limite de genre. S'en détachent la prose poétique d'Oswald de Andrade ou les chroniques-journaux de L'apprenti touriste, élaborés par le regard narquois de Macounaïma. Bien que la construction de la rhapsodie soit distincte formellement du journal, ne répondant pas aux critères spatio-temporels, entre autres, le lecteur a l'impression d'être le narrateur configurant l'écriture littéraire par l'aventure du voyage. La première incursion en Amazonie a contribué à enrichir l'univers fabulateur de la rhapsodie, malgré le fait que la recherche avait déjà été faite dans des livres. Lors du deuxième voyage, la vérification et le perfectionnement 
du matériel folklorique de la région ont été transposés en chroniques et reçu un traitement également propre à la fiction.

Par le genre de la chronique de voyage, le narrateur permet au lecteur de se représenter réellement les danses, les musiques et les histoires racontées par des tiers, laissant dans le texte l'impression d'être à la fois documenté et de participer de l'expérience relatée. Le Nord-Est lui arrive par l'ouie, la vue et l'odorat, incorporé dans le chant plein de vie des poètes-chanteurs et interprètes de la culture orale et de sa vitalité. La parole chantée du Nordestin, interprétée comme mélodie, place ce dernier dans le climat festif des coqueiros [chanteurs de coco], dans la musique des chants de vaqueiros [ceux qui conduisent les troupeaux], dans le lien entre travail et loisir. La collecte du matériel folklorique n'aboutit plus à l'énoncé froid et distancié du chercheur, mais se cale sur la sensibilité du poète, s'incorporant au chant qui se configure par le vécu et par le geste postérieur de l'écriture. Si les danses dramatiques et les chants mettent en scène des situations que les spectateurs peuvent partager, l'écriture de voyage accompagne ce mouvement et invite le lecteur à entrer dans la danse. C'est là que réside le degré élevé de dramatisation de l'écriture marioandradienne, lui attribuant le statut ambivalent de chronique journalistique et de fiction.

Je me couche après ce premier jour de Noël. Dans un tel état que je ne peux m’endormir de bonheur. Je m'étire dans le lit et le vent arrive, bat en moi en chantant tel un « coqueiro ». On appelle par ici « coqueiro » celui qui chante des « cocos ». Non, il ne s’agit pas d'un végétal, il s'agit de l'homme le plus chanteur de ce monde : le Nordestin. [...] Le vent chante. Les petits oiseaux, les gens du peuple passant. L'homme qui mène et ramène les vaches d'ici d'à côté, ne travaille pas sans chanter son chant sans paroles ... Ici à la maison aussi. Nous chantons tous, des cocos, des embolados, des sambas, des dobrados (marche militaire), des chansonnettes ... (Andrade 2015b, 275)

La reproduction de chants au son des clarinettes et des ganzes, l'entrée du narrateur dans les réjouissances populaires indiquent le rôle réceptif du chercheur/ écrivain dans le texte, par l'emploi de la diction qui se rapproche de la rhapsodie de Macounaïma. Dans la revitalisation des rites et des chants populaires est mimétisée de façon sensorielle la valeur littéraire de la rhapsodie, sans qu'on la confonde pour autant avec la chronique de voyage. Elle se distingue encore de l'écrit des anciens chroniqueurs, plus intéressés par la description de l'exotique ou de l'étrange tel que le voit le colonisateur. Texte, danse et musique se mélangent dans la vision du voyageur, constituant une matière homogène et reflétant l'esprit ingénu et joyeux d'une communauté. L'oisiveté, la vision du spectacle allongé dans le hamac, pointe la relation paresse-savoir, sensation propice à l'affabulation : «Vient un choro. Clarinette, guitares, ganze dans une suite délicieuse de sambas, maxixes, varsas de pure origine, moi dans le hamac, passant le temps 
sans rien dire. Chansonnettes de Ferreira Itajubá et Auta de Sousa ... La nuit est tombée sans que nous nous en soyons aperçus. » (Andrade 2015b, 299).

Dans les observations les plus touchantes de Mário de Andrade se trouve la figure de l'homme commun, du prolétaire, du chanteur/travailleur et du peuple. Chant et situation sociale s'entrelacent dans le tableau ethnographique dressé de la région, dans lequel on constate la vision quelque peu naïve et l'idéalisation du narrateur, animé par les défis et improvisations chantés (la cantoria) du Nordestin. Si la propre diction de l'habitant reçoit le même traitement, il s'avère néanmoins prudent de ne pas négliger le penchant de Mário de Andrade pour le choix de la musique comme une des possibles échappatoires aux problèmes d'un peuple marqué par la sécheresse et la misère. Le savoir des chanteurs incultes et des acteurs des danses typiques de Noël et du Nouvel An sert de contre-chant à l'art considéré comme cultivé, raison pour laquelle le narrateur insiste pour les valoriser. («Les gens d'ici sont joyeux et à chanter autant qu'eux je ne sais ce que l'on chante », Andrade 2015b, 300). Le concept d'art populaire s'empare autant de la position sociale des interprètes que de la manière singulière de réunir chant et vie, document et fiction.

L'illustration la plus éloquente de la cantoria du Nord-Est du Brésil se trouve dans la figure emblématique de Chico Antônio, le chanteur que Mário de Andrade rencontre à l'engenho (exploitation sucrière) du Bon Jardin, dans l'état du Rio Grande do Norte. Le portrait qu'en brosse l'auteur, tout comme celui des autres artistes anonymes de la région, a le mérite de redéfinir des concepts et de reposer des questions relatives aux critères attribués à la dimension populaire, bien usée, de la culture et aux préjugés relatifs au populisme. L'admiration de Mário de Andrade pour la performance et le talent du chanteur nordestin condense les images de l'artiste du cru, de l'improvisation et des variations mélodiques créées au gré du moment. La forte présence de l'artiste et son interprétation exhaustive pendant des heures, au son du ganze et inspirée par la boisson, provoque l'exaltation et le délire de celui qui assiste au spectacle. Mário de Andrade fait de Chico Antônio le héros de cet art populaire et le personnage principal du voyage au Nord-Est.

Il choisit encore le ganze, instrument dont il joue, comme titre du projet inachevé Na pancada do ganzá [Dans le frappé du ganze], où il prétend réunir le matériel collecté sur la musique populaire nordestine ${ }^{1}$. Comme métonymie de la recherche, on trouve Chico Antônio comme sujet inspirateur, pour se détacher du

1 Les sections qui se réfèrent à la musique de sorcellerie et aux danses dramatiques ont été édités par Oneyda Alvarenga, en trois volumes intitulés Danças dramáticas no Brasil [Danses dramatiques au Brésil]. 
cadre de l'art populaire et représenter tous les autres. Il sera aussi un personnage du roman inachevé Café, publié à titre posthume, dans la figure du Nordestin qui refait sa vie à São Paulo (Andrade 2015a).

Dans la performance désintéressée et auto-suffisante du chanteur, la ressemblance avec la poétique/la vie de Mário de Andrade se confirme, soumis qu'il est au plaisir de la création excessive, à l'exercice de la dépense comme règle. L'art de vivre sans limites, la soumission à la douleur comme au bonheur se reflète dans l'attitude artistique/vitale de Chico Antônio, son côté humain prolétaire et sensible aux manifestations populaires. La mise en scène musicale de l'artiste renvoie de même aux rhapsodes et au processus parodique de Macounaïma, quand Mário de Andrade évoque l'improvisation et la « trahison de la mémoire » comme instrument créatif et abandon des modèles hégémoniques européens. Entonner sous la forme d'emboladas les mélodies du bœuf et les cocos nordestins, qui attirent les « hommes du peuple », est une pratique qui ne s'épuise pas en quelques heures, Chico Antônio ayant opté pour l'excès et le plaisir. Aux yeux du narrateur, son comportement égale celui de l'oiseau qui chante gratuitement, comme entité de la nature : "Si on chante la nuit entière, la nuit entière les travailleurs restent ainsi, cercle de gens assis, accroupis autour de Chico Antônio l'oiseau irapuru, sans pouvoir partir. » (Andrade 2015b, 317).

Chico Antônio reçoit du narrateur les plus grands éloges en tant que représentant de l'artiste nordestin et comme symbole de perfection et recherche, enregistré pour ses astuces dans l'embolada et l'improvisation. Son type physique va enrichir l'image divinisée, alimentée par la performance de l'homme humble, avec ses phrases issues du labeur quotidien et de l'amour. Mário de Andrade s'extasie avec l'émotion provoquée par le spectacle du chanteur, au point d'établir avec lui une relation de complicité et d'extrême convergence :

\footnotetext{
Mais Chico Antônio dépasse de beaucoup ceux que j’ai écoutés, par la force vive de ce qu'il invente et la perfection avec laquelle il entonne son embolada. Grand, corps d'homme du Sud, maigrelet, un peu lent dans le geste long, une gueule horizontale, bien aplatie et sympathique, de Nordestin en marge. Des yeux merveilleux, je l'ai déjà dit. Et la voix incomparable. (Andrade 2015b, 317)
}

Le concept même de moderne présente chez l'écrivain des variations, si l'on compare les saisons lyriques de São Paulo avec le chant de l'embolada de Chico Antônio, ou lorsqu'il le considère supérieur à Caruso, le fameux interprète d'opéra. Les dissonances du chanteur dépassent les "dissonances chics des Modernes », pour introduire la dimension populaire et la différence par rapport à la définition canonique du modernisme, détachée de la tradition et prise à la nouveauté, à l'avant-garde et au cosmopolitisme. Cette interprétation donne une suite logique aux découvertes du voyage au Minas Gerais en 1924, un moment significatif de 
changement et d'ouverture aux différents versants d'une modernité définie comme vernaculaire et périphérique. Les couleurs de la nature, provoquant l'intérêt de Tarsila do Amaral et de son art pour les tons « arriérés » et particuliers du populaire, tout comme le dessin des petites villes, sont encore évoqués par le regard de Mário de Andrade sur le Nord-Est. Art et nature se conjuguent dans la description également exagérée des tenues cérémonielles des figurants de la Ciranda (Ronde), dans laquelle les couleurs des costumes et les danses composent le paysage reproduit par Tarsila, une des transformations opérées à cet endroit dans le concept spécifique de modernité. La vision du narrateur, médiatisé par l'art, définit le milieu de façon distanciée et fictionnalisée, l'incorporant à la conception esthétique moderniste et à la fonction identitaire de la culture brésilienne :

Les tenues cérémonielles sont criardes et savoureuses à voir. Chapeaux inspirés des coiffes indiennes, pleines de plumes d'aras, fleurs en papier et naturelles ; blouses et culottes de couleur claire, rose, chair, jaune, vert, les mêmes couleurs crues avec lesquelles Tarsila a si savamment brésilianisé ses tableaux. (Andrade 2015b, 414)

Sans qu'elles formulent le moindre propos discriminatoire, les manifestations artistiques pourront cohabiter en relation étroite, dans la mesure où ne seraient pas mis à l'écart d'autres composants culturels. La position de Mário de Andrade a toujours été soutenue par une lecture de la notion de modernité comme expression de l'échange entre le national et l'étranger, l'érudit et le populaire, avec le respect des différences locales et singulières, où la perspective périphérique agit comme stratégie de résistance et d'intervention, accentue les différences et permet la récupération de domaines exclus de la culture.

\section{Bibliographie}

Andrade, Mário de. Café. Tatiana Longo Figueiredo (éd., préface, introduction et sélection d'images). Rio de Janeiro : Nova Fronteira, 2015a.

Andrade, Mário de. O turista aprendiz. Telê Ancona Lopez et Tatiana Longo Figueiredo (éd., notes), et Leandro Raniero Fernandes (compléments). Brasilia : Iphan, 2015b [1976, posthume].

Clifford, James. A experiência etnográfica. Antropologia e literatura no século XX [L'expérience ethnographique. Anthropologie et littérature au XXe siècle]. José Reginaldo Santos Gonçalves (éd.). Rio de Janeiro : Éditions de l'UFRJ, 2008. [The predicament of culture: twentieth-century ethnography, literature and art. New York : Harvard University Press, 1988].

Figueiredo, Tatiana Longo, et Telê Ancona Lopez. « Por esse mundo de páginas » [Par ce monde de pages]. Mário de Andrade. $O$ turista aprendiz. Brasilia : Iphan, 2015b. 
Eneida Maria de Souza is a Professor Emeritus of the Federal University of Minas Gerais, Brazil. She received a PhD in Comparative Literature from Paris VII University. She is a former director of the Brazilian Association of Comparative Literature (ABRALIC, 1988-1990), and the author of the following works: O século de Borges; Janelas indiscretas - ensaios de crítica biográfica; Crítica Cult; Modernidade toda prosa (in collaboration with Marília Cardoso). Co-editor of the Correspondência de Mário de Andrade e Henriqueta Lisboa. 
